Studia UBB \$ligitalia, Volume 63 (LXIII) 2018, June, Issue 1, 81-96

Published Online: 2018-06-30

DOI:10.24193/subbdigitalia.2018.1.06

\title{
Methodology for Creating Data Visualization. A Case Study for Interdisciplinary Timelines between 1750-1900
}

\author{
Voica Pușcașiu \\ Babeș-Bolyai University, Cluj-Napoca
}

\begin{abstract}
The present study was originally aimed at creating a helping tool for teaching and understanding art history through the use of visual schemes. Despite the fact that timelines are often present in both history and art history books their status is rather that of footnotes (Wolf, Gombrich 656-663, * * * 392395) and a study for their methodology and usage was truly lacking. Considering the way in which simple data visualization can comprise vast amount of information and deliver it in an efficient manner, it makes it worthwhile to ensure its scientific quality and accuracy through proper methods, as well as to actually creating ones that are both simple and eye-catching. Thus this paper is a result of a personal interest in the development of such tools and the challenges encountered along the way. Offering valuable information in a short glimpse through simple graphics over the life and the artistic creation of various artists is only enhanced by the opportunities provided by digital tools and the virtual environment, so it is perhaps an auspicious time to start seriously considering this type of research.
\end{abstract}

Keywords: digital tools; data visualization; visual schemes; timelines; learning

\section{Introduction}

Seeing as though the beginnings of this research date back some years to when the realm of Digital Humanities was relatively unknown, especially in Romania, the very first obstacle it encountered was the delivery method of the visualizations. So lacking the concept of interactive use of the timelines the very first projects were simple image-based documents fit either for a screen, or eventually even for printing. 
Also due to the fact that everything had to fit in one single image, the greater scope of offering a global, long-term view in a single picture was unfeasible and had to be abandoned. This of course led to the creation of separate images for various time frames: one spanned from 1250-1600 (Fig. 1) and contained the Renaissance masters, 1450-1700 - the Baroque era (Fig. 2), 1650-1900 (Fig. 3), the Impressionists 18001950 (Fig. 4) and the modernists between 1850-2000. The overlap was of course intentional as they were meant to be used together rather than singularly. Through these images the aim was to demonstrate a certain simultaneity and concordance between contemporary artists even those living and working in different countries, and for each period a number of 25 artists were chosen, each also represented by 23 significant artworks. The manner in which they were received, both by fellow scholars, but also by younger students has proved, be it only on a personal level, the relevance of a synoptic vision in the field of art history and more so in the way this could be connected to the larger field of history.

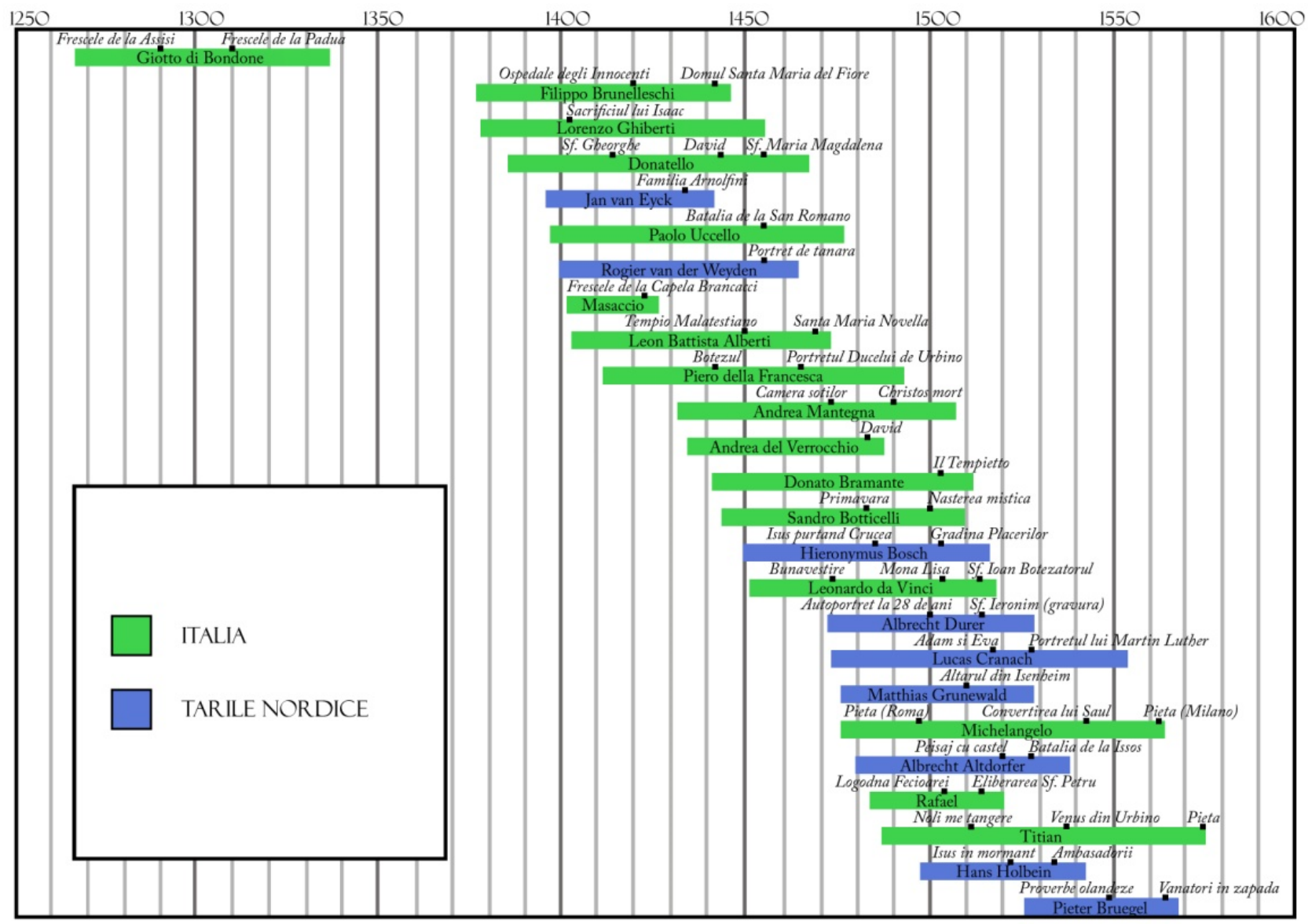

Figure 1. Timeline of artists between 1250-1600 


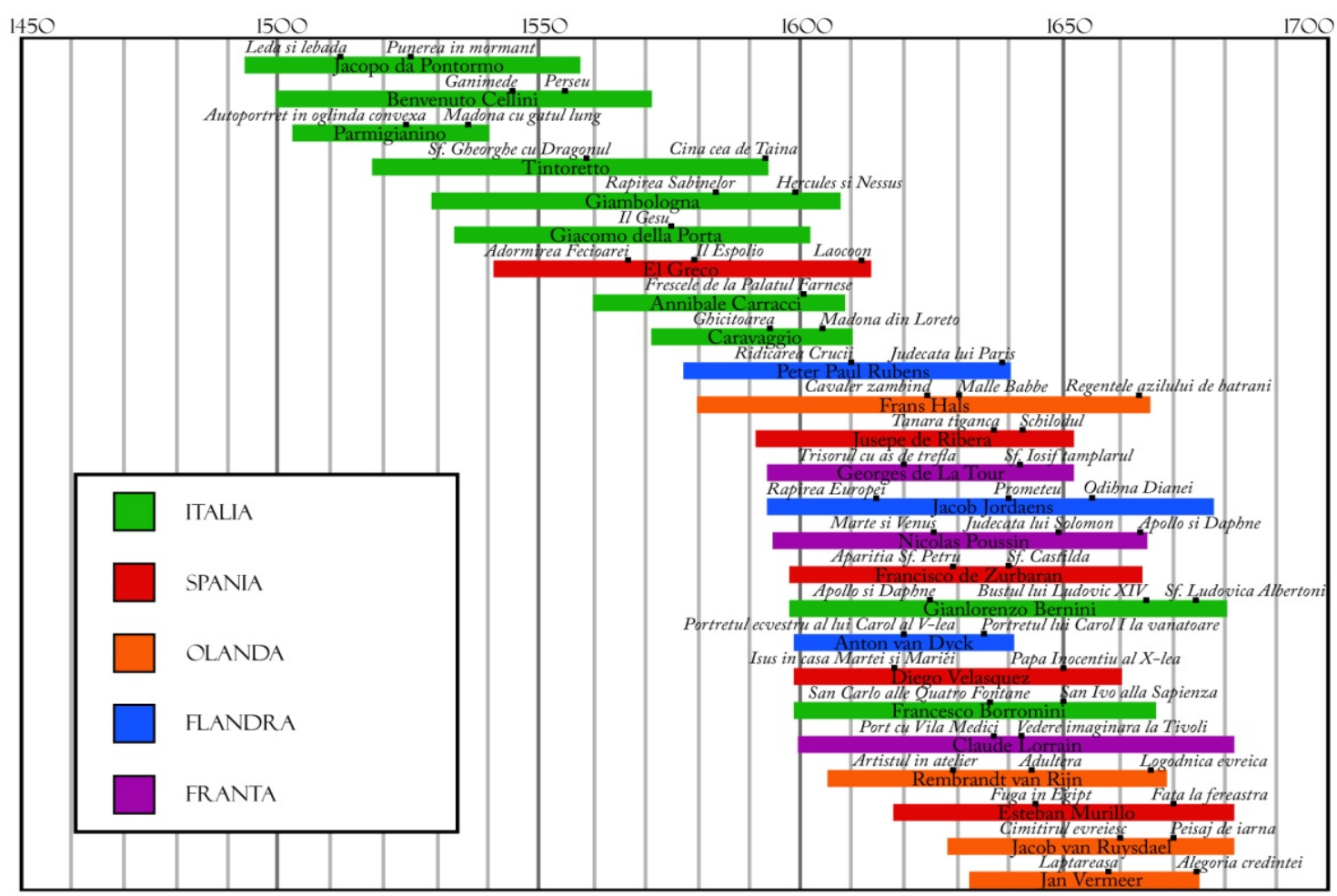

Figure 2. Timeline of artists between 1450-1700

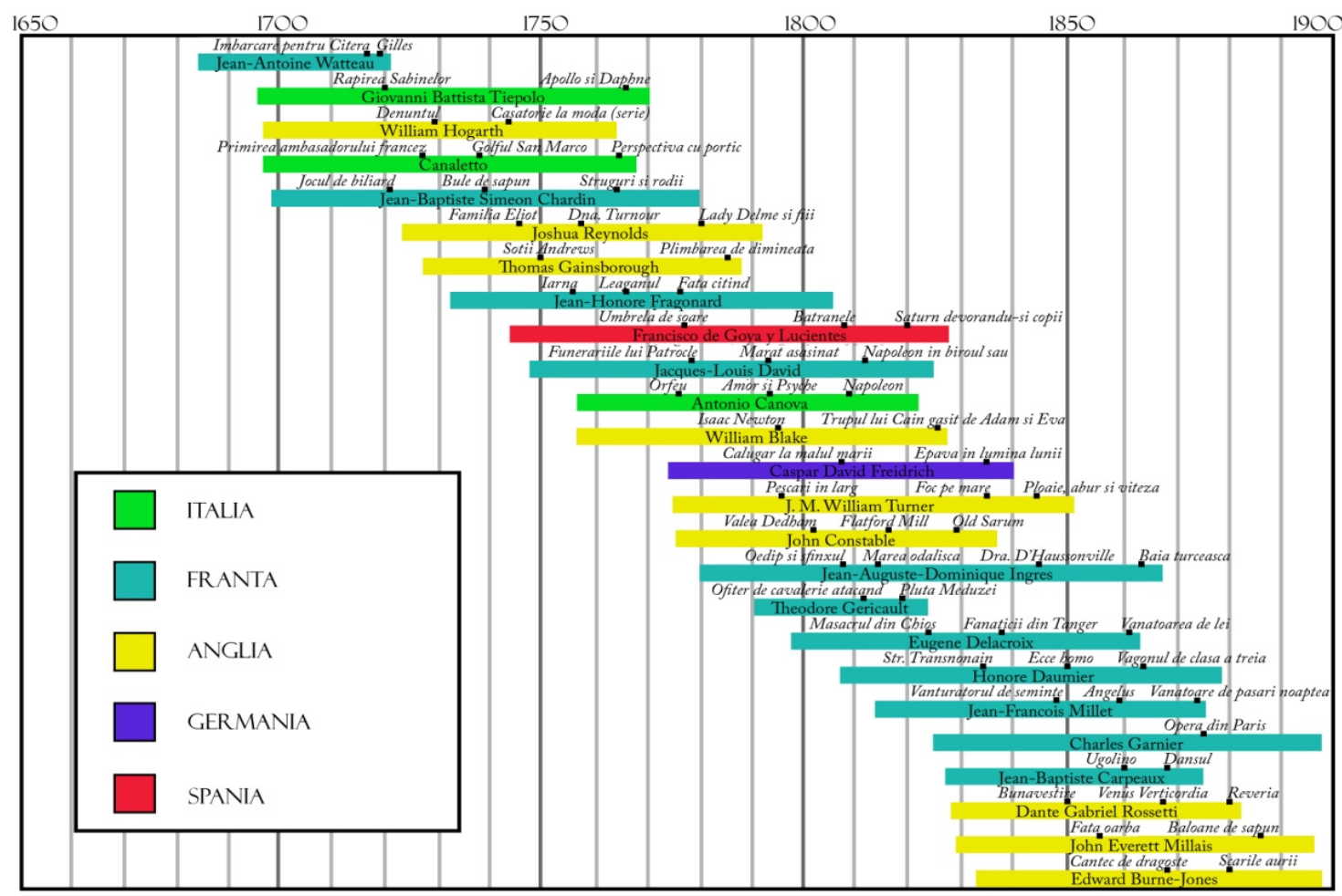

Figure 3. Timeline of artists between 1650-1900 


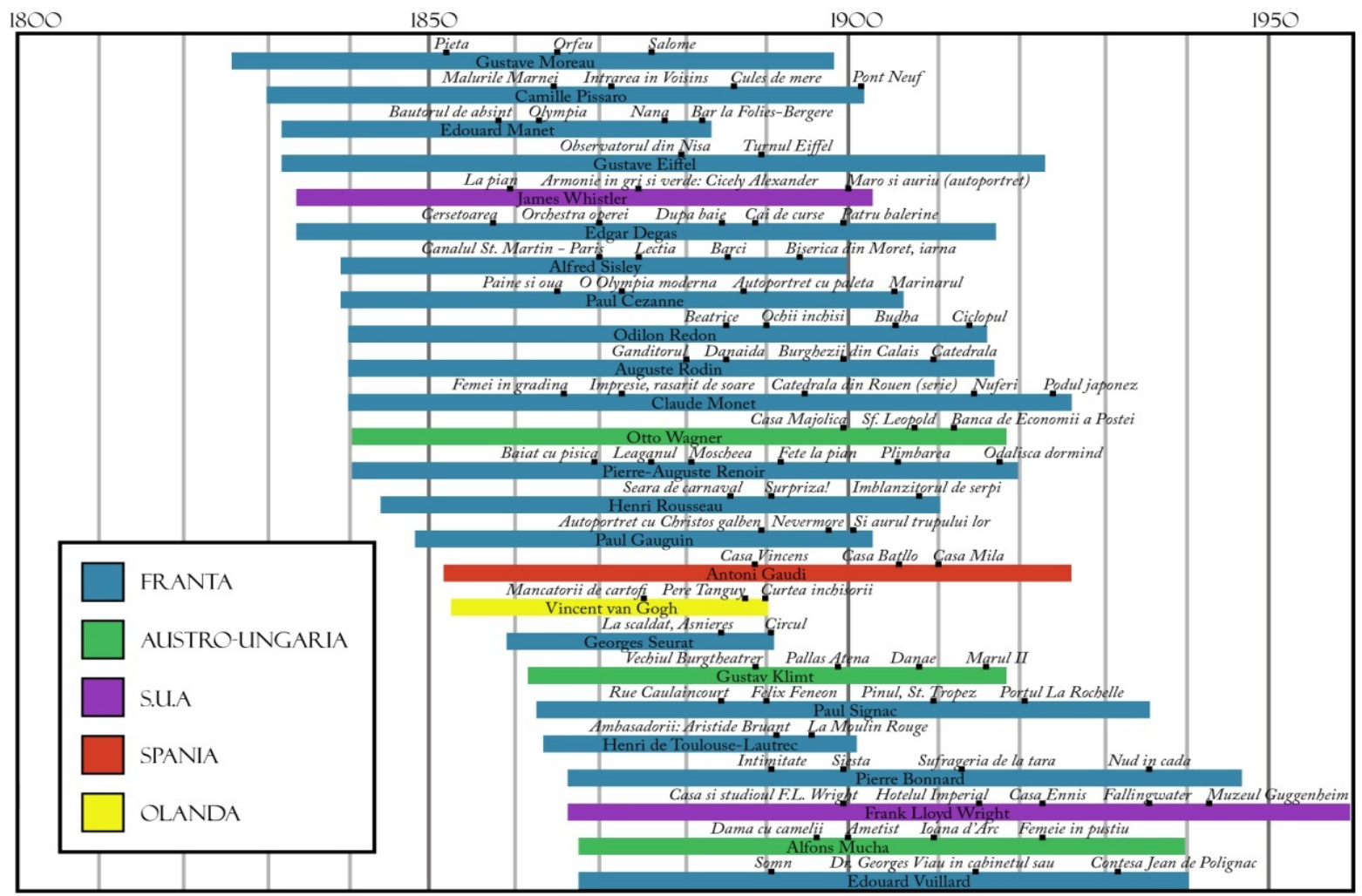

Figure 4. Timeline of artists between 1800-1950

The general lack of simultaneously presenting in front of a classroom both historical and artistic events that take place at the same time but maybe in different geographical spaces, although understandable due to sheer lack of time, makes for a biased understanding of said events. They often lead, in the younger minds of students towards a fractured picture of the era as if these events happened independently from one another, particularly when the connections are more subtle. For example when it comes to teaching Renaissance art, there is always a clear distinction between Italian and Northern manifestations, and more often than not, it is always implied that the second derived directly from the former. It is thus lost in this oversimplification, the fact that the masters of Northern Renaissance were contemporaries with those of the Italian Quattrocento, a fact which is almost never mentioned, nor particularly implied. The sheer vastness of European Baroque as well as its geographical particularities also means it is fit to be taught in the sense of national schools - first Italian, then Spanish, then Flemish and eventually Dutch and the French Classicism is in a group of its own - again greatly fragmenting the greater picture. Timelines come in to bridge this gap through a simple visualization, the picture is complete again: you can find out rather surprisingly that Gianlorenzo Bernini was a contemporary of Claude Lorrain, 
and that they were both still alive and still working during the untimely death of Jan Vermeer van Delft. These three masters, are never presented simultaneously due to the great geographical and stylistic difference between them, but this only deepens an unjustifiable gap and creates an erroneous picture of the time frame in which they belonged, somehow making it seem more uniform that in actually was.

Things get increasingly more complicated as we venture on, since art history, taught and written predominantly as a history of styles, seems to be unable to manage individual personalities that do not easily fall in a category - just look at the examples of Goya, Ingres or Constable, which are rarely mentioned among their contemporaries. Concerning modern art, things are more difficult still due to the multitude of currents, isms, and artistic groups which are active during the same time. Timelines do not become less valuable or less interesting, but rather through them one can take note of how a certain geographical space is favorable for a certain style or aesthetics. Just like as the German Expressionists and the French Fauves have very different approach and results despite the fact that they fully overlap time-wise.

A particularly interesting aspect of the timelines, specifically from a pedagogical perspective, is that they are perfectly suited for an interdisciplinary view, something which is no small feat, especially in this day and age where most domains tend towards such an approach. Thus the size and complexity of such visualizations is limited only by the discourse that they follow. A timeline can simply be an axial section - even for one single year which is particularly interesting for one's research and it can contain worldwide events from the most varied of domains and activities (history, literature, fine arts, music, science, medicine, sports, etc.). Until then this has been a rather rare method of using timelines, obviously limited by the printed medium, but exceptions still exist (Wolf). But this is ultimately unfortunate, because it is of course easy to see and say that artists are influenced by one another, but it is not less true that they are also influenced by many other factors as well - history, literature, music - and that the influences often go both ways! Seeing that art is at a loss when taken out of its larger sociological context (Hauser 6), a point should be made to offer as large a context as physically and visually possible (Gariff).

\section{The Methodology of Constructing a Timeline}

\subsection{The Need for Interdisciplinary Timelines}

The main reasoning behind the creation and use of timelines basically comes from the fabled ignorance over the proper chronology of facts. As with history itself, art history is also tributary to the principle of causality, so for the truthful knowledge 
over a phenomenon, first one must be aware of its source. Timelines offer the opportunity to view these chronological facts in an explicit way. Since the source of art often stems from historical events, literary works, or contemporary personalities, the need for synoptic charts $(* * * 392-395)$ or timelines for multiple fields, is quite obvious. Consulting a graphic scheme makes the discovery of connections much easier and also helps in quicker remembering the "landmarks". From all the aforementioned interdisciplinary connections the most important one is the one the arts have with history. In the case of historical events, the direction of the influence is notably a one way street: there are perhaps thousands of artworks illustrating various wars and conflicts for example, but there is yet to be a war that started from a work of art. Just like La Marseillaise provided the soundtrack for a revolution, and Delacroix's Liberty Leading the People gave it a symbolic image, along with Gavroche that dies on the barricades in Hugo's famed novel - all of which creating an assembly of the era, but none of which actually influenced the developments of the French Revolution. And such examples can go on and on. What is interesting though is that the need for connections, even though not quite so evident, still remains even for works that are not so deeply embedded in propaganda, be it only for the relevance they have for other fields such as music, or literature, but also since no work of art can truly and definitively be extracted from its historical environment.

The interdisciplinary ties and influences perform in a crisscross manner and on multiple levels: fine arts and history, literature, and music, literature and music, history, literature, and music respectively. Due to this great number of complex variations the need for an encompassing timeline chart is clear. In order to build a data visualization that is as close to the true dimension of the phenomena the only feasible solution, that can begin to depart from the utopical realm is employing digital means. One cannot obviously view everything all at once, not even on a scheme, but nor do they need to, however through an interactive timeline that uses filters and or layers the viewer/user is offered a great number of options so that the timelines become useful in individual and general ways.

Besides the interdisciplinary connections, the timelines have an indisputable added benefit, namely that of creating connections between artists and their themes. These can function among contemporary masters but just as well among those separated by long spans of time. Through timelines one can observe the iconographic evolution of a particular theme or motif with the constants as well as the mutations in the representations and concepts. For example one can trace the modifications brought in the representations of David during the Renaissance and Baroque from Donatello, to Verrocchio, to Michelangelo, and ultimately to Bernini and better analyze their 
stylistic differences. But on a larger time frame one can also observe the frequency of certain poses such as a reclining nude that can all be traced to Giorgione's Sleeping Venus (c. 1508), first through the takeover of the much more famous Titian (1534), but then also through the more modern replicas of Ingres (1814), Manet (1863), Matisse (1935) up to the statement of the Guerilla Girls (1989).

This is without doubt a very rich subject and it is also here where the bias of the discourse also comes in. When selecting the artworks, and even when creating the filters, the author of the timelines can lead the visualization the way they see fit. Or even if they choose to be objective, the user can ultimately select whatever it is that they see relevant and thus interpret the data in a very subjective manner. However we should not consider this as a pitfall for timelines themselves, much more than it is proof of a subtlety that is not necessarily apparent when one first comes upon them. It is perhaps best to acknowledge it and proceed forth with caution, and not take them utterly for granted as always being truthful, just as a good scholar would do with any tool or historical text, where critical thinking is expected to be employed.

\subsection{Applicability of Timelines for Various Historical Eras}

As we have shown before timelines are not limited to a certain period, but the same principles should be followed in order to create a timeline for any era or even for a longer-spanning historical even versus for a single year. Of course the specificity of the period should always be taken into account. A relevant example is the timeline illustration in Gombrich's famous volume (656-663), suggestively titled 5000 Years of Art History comprising the time span between 3000 B.C and 2000 A.D. The vertical columns belong to centuries, while the horizontal lines mark the geographical spaces according to their past and present relevance. On this single chart you can see the extension of various styles and cultures beginning with the Akkadian one and ending in Postmodernism. What is striking at first glance is how much the span in time shrinks for each style as if time really started to flow faster. Thus the Middle Kingdom of Egypt and the Bronze Age in Crete-Mycene both span approximately 600 years or so, the Gothic is only about half as long. The "lifespan" of currents from Renaissance to Romanticism is of only 100 years, with the first also being the longest running, and they are followed by the drastic compression and congestions of styles in the modern era from Impressionism to Op Art that has a span of approximately 20 years.

All of this ultimately means that the graphics need to be both consistent in order to maintain the same structure and relevance, but also adaptable enough as to accommodate each era and to be just to its specificity. Needless to say from a 
strictly visual point of view and also from the challenges in delivering an efficient visual scheme - the timelines themselves tend to get increasingly more crowded as time moves on. But as we have seen this is not necessarily something that cannot be overcome.

\subsection{The Content of the Timelines}

Considering the data itself and the information that is to be available in the timelines, these will always be in direct connection to the discourse the timeline author favors, and in this sense they can become rather subjective or take into account very narrow themes. For example if the interest lies in following equestrian statues throughout history, then those particular examples will be chosen or highlighted. Thus the situation might arise that some notorious artists could be potentially left out since they did not approach the equestrian theme in their careers, just as well as some lesser known artists might make an appearance due to the fact that they focused on animal, particularly horse sculptures. Also it is worth to mention that the time span itself is also left to the decision of the author. In this sense the timelines will not be crowded and they will be extremely efficient in a narrow iconographical study.

There is no right or wrong way to construct a timeline as long as it suits the needs of a research as long as one stays true to the data and of course the chronology. However a greater scope would be that of offering a holistic view over the course of art history. This goal should be approached with realism as there are a great deal of general art history books and textbooks that claim to be exhaustive and yet they are far from that. This rings true for graphic representations and data visualization as well since the tendency to overcrowd them is not at all beneficial as it will make them impossible to read and thus render them useless. So, even though the present case study is aimed toward a "bigger picture" it is still conditioned by certain spatial limitations. These limitations are greatly expanded in the digital medium, but they are there nonetheless, and a more honest approach would be to be conscious of them and focus on capturing the essence and the main protagonists, similar to Gombrich, which still proves timeless.

According to this principle, the selection used for the timelines presented here

have been conditioned mainly by the degree of presence artists have in art historiography especially when considering textbooks or general art history texts. There are of course artists and authors that could not have been left out of any scholarly research even if only because of the fact that they are too deeply embedded in the collective conscience. The usual suspects so to speak. No matter how redundant the 
presence of Picasso, Dickens or Beethoven might seem, their inclusion is compulsory specifically because they are so well-known and popular and can be used as a milestone for the readers. Even when addressing a more elevated audience their presence is still useful as it can serve as the scaffolding for the entire project.

Another criteria strictly connected with the first is the degree of popularity the artists have among the viewers. The more popularized they are, the further along in the collective memory and attention they are, and thus there is an ever increasing interest in their work, albeit on a more superficial level. It is beyond the scope of this research to unravel or judge the obvious stereotypes and they have thus been included. More rarely the criteria of popularity during the artist's lifetime has also been used, even though they might have fallen out of fashion later on, or they had little to no influence in the development of artistic styles. Such is the case of the Academists whose popularity was neither the result of genius, innovations or influences, but rather directly connected to their context and current ideology. Their art was already considered obsolete during their lifetime, and are largely left out of general studies, but they have had a considerable presence which is not easily ignored for the sake of truthfulness of the epoch.

The most relevant and valuable criteria are those that reference the implications of the artworks or better said their influence over other artists. In this sense certain artists that have had a considerable influence be it on their contemporaries or further along down the (time)line. These models are of higher value than popularity, or a particularly interesting biography. Just as a new style does not come out of thin air, the particularities of a period will be superficial if one does not acknowledge the initial starting point. This is why it is of high importance that the timelines marks the beginnings and the permutations of a model and its conclusions.

Besides the stylistic innovations, attention must be paid to the technical ones that have since propagated. This can be either a new technique in sculpture, or the pioneers of oil painting, or even photography. These innovations are often interdependent with stylistic ones just like oil paints offer a different aesthetics than water-based ones, and so the medium an artist uses is just as important in an analysis of his works, and one might notice a predisposition for one manner of the other. Yet another major criterion laid in identifying not only the artists that bring along a new style, but also those that provide the peak of a current. The degree of interference provided another reason in the choice of artists, especially considering the interdisciplinary nature of the timelines. In this case it must be mentioned that it applies rather to the choice of works than to that of the artists themselves. 
Due to the fact that the very first difficulty lays in the immediate sense that a style-based art history is inefficient offering a global perspective on art and causes major rifts in chronologically overlapping eras, the present case study has been chosen as a fixed period of time and was meant to offer a cross-section through many currents. Specifically they are artists born between 1750 and 1850 regardless of their style. This hopefully proves the full potential of the timeline visualization, as complete and as objective as possible. The chosen time frame thus passes through a number of styles, demonstrating the universal applicability of timelines. This was also done for the connected domains I have mentioned beforehand.

For the art history layer of the timelines a number of 32 artists were chosen, from Henry Fuseli (1741-1825) to Vincent van Gogh (1853-1890). Concerning the layers dedicated to literature and music the criteria for choosing the authors was the as described above for artists. Thus the literature layer contains 28 authors from Goethe (1749-1832) to Oscar Wilde (1854-1900), philosophers like Hegel, Schopenhauer of Nietzsche, but also art historians. The composers are the least represented, numbering 17 of them from Mozart (1756-1791) to Debussy (1862-1918). The criteria here were much stricter and followed those who brought an immeasurable record in universal culture or have been in a deep relationship with artists and writers.

The history layer contains events of major involvement like the two World Wars, but also national events that had repercussions on the fate of the entire continent, such as the French or the Bolshevik revolutions. Important historical characters have also been marked like Napoleon or Queen Victoria whose reign defines an entire epoch, Otto von Bismarck or Abraham Lincoln.

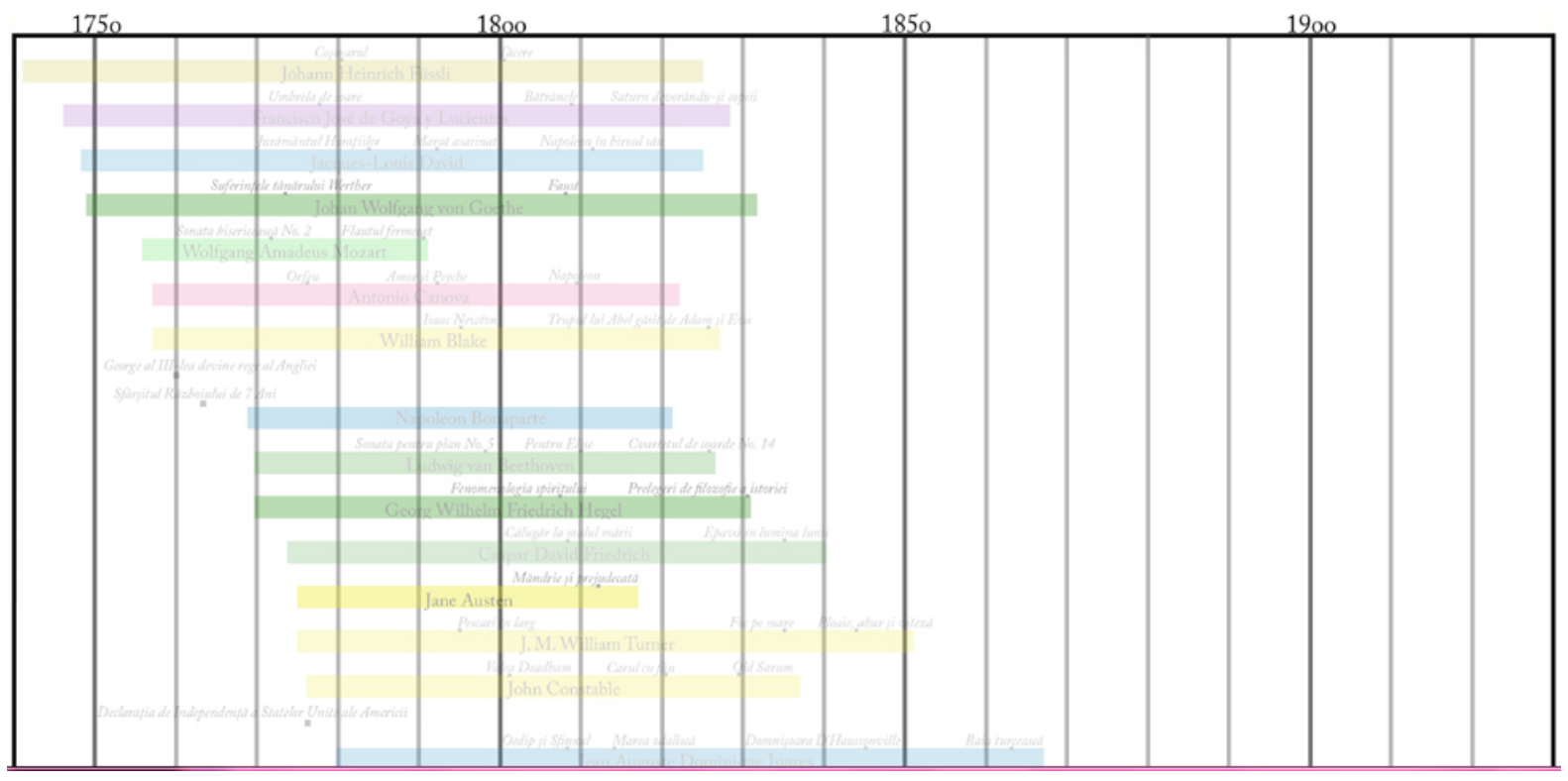

Figure 5. Detail of 1750-1900 timeline with all four layers in various opacities 
When it comes to the chosen artworks, a couple examples have had to suffice, but an effort has been made in choosing relevant artworks from various stages of an artist's life and career. In the case of the literature stylistic changes are harder to pinpoint, and thus the most remarkable writings have been chosen, same as with philosophers. A different facet is however the writings on art which easily mark the values of an era and the way they are reflected in contemporary art. For example Wincklemann's eulogy of antic art is perfectly inscribed in the revival of classical values and their imitation (Tătaru 13) as seen in the works of Jacques-Louis David. Or the influence John Ruskin's works have on the revival of the Gothic and on the art of the Pre-Raphaelite Brotherhood (Ruskin 55, Marin 19).

Concerning musical works the compositions were chosen on the degree of popularity and relevance, a task which proved difficult due to the large number of works by the same composer. The focus on art history is of course the visible bias in this methodology, since if it were created for a different field the proportion would have been reversed. But for now, the main motive behind the choices lay in their capacity to establish clear interdisciplinary connections.

Such examples are the Edgar Allan Poe's poem The Raven (1845) and Paul Gauguin's painting Nevermore (1897). A direct relation between a writer and an a composer that is easily observed is Stéphane Mallarmé's The Afternoon of a Faun (1876), the musical replica belonging to Claude Debussy Prelude to the Afternoon of a Faun (1894), and yet another example is Emile Zola's novel The Masterpiece based on the life of Paul Cézanne, and which eventually caused a permanent rift between the two former friends (Rewald 19).

The nuances and examples shown here are meant to demonstrate how flexible these timelines can be, as they are suitable for a large number of discourses and uses. Also one can note how varied and complex the information gathered from them can be, despite their apparently simplistic appearance. The challenge in creating them being to not make them appear too crowded or filled with apparently useless data, but in the same time to be able to maintain all the coordinates above in order to infuse them with as much meaning as possible.

\subsection{The Graphic Aspect of Timelines}

Simply and honestly put, the way in which the timelines look is an extensively important factor in the way they are perceived and even used. The rules here are however pretty simple and common sense - a clean, unambiguous design, an easy to read font in a suitable dimension are aspects that concern their ultimate level of 
success and popularity with the users. The importance of the visual aspect of an informative tool, especially one meant for teaching is recognized by educators and ideally these should appeal to the intellect of the user but also as much as possible to strike an emotional chord (Felezeu 7).

In a graphic sense, timelines are made up of a sort of table where the years are represented by the vertical lines and the horizontal bars represent the lives of the artists. This is pretty standard for timelines in general (Admiraal 53). In this particular case the markings are for every decade and not every year, and a darker tone marks every half century. The horizontal bars are inscribed with the name of each corresponding artist and the artworks are marked by dots according to the year in which they were created. The artists have been placed in descending order according to their year of birth and in the case of artists born in the same year, the one that passed away younger is placed above. The only exception is to be found on the history layer, since most of the notes there were not personalities but rather specific events which were marked as self-standing dots, similar to those that mark the individual artworks.

In the case of these particular timelines the colors are also important, as they add yet another piece of information, but in a non-aggressive manner. The bar designated for each artist has different colors according to his place of birth. Thus along with his lifespan it offers the minimal amount of biographical information, but also it can help with placing the said artist in a group with his co-nationals from different fields. Another yet more important aspect is the fact that a so-called red wire can be traced among the tendencies of a geographical area as distinguished from those of another.

An interesting aspect arises from the use of different color, such as the preference of certain countries or areas for different mediums in various eras. For example you can easily note the fall in the dominance of Italian artists to be replaced by the French, or the way the Netherlands make a comet-like appearance during the Baroque era. Due to the introduction of color, the timelines necessarily have a reading key explaining what each color stands for (Fig. 6), but this is easily integrated and does not distract from the visualization itself. For now the colors strictly represent the place of birth of the artists despite the fact that they might have lived and worked in a different one. This is quite a contestable decision, however it opens up the possibility to change to color on a bar according to the travels and movements of the artist in his lifetime, thus introducing yet another piece of the "puzzle". 


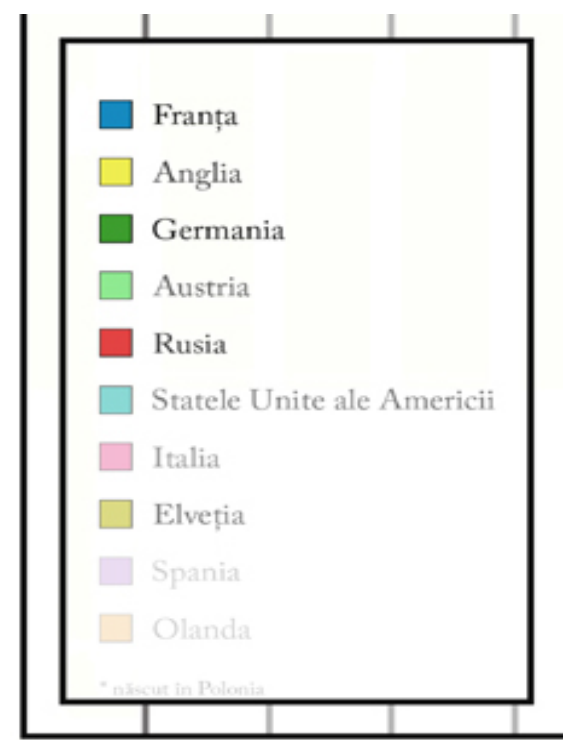

Figure 6. Detail of the color scheme key for the timeline between 1750-1900

New information that can be gathered from the color scheme is to notice how some zones excel in a medium while being completely unremarkable in others. For example the Russian area which brings us writers and composers of an incontestable value, especially in the time frame we have analyzed, and yet the red is missing from the art history layer altogether. France on the other hand is completely the opposite as it has only one composer but makes up for it with the large number of artists.

\section{The Pedagogical Destination of Timelines}

These chronological chats have been conceived as didactic materials, stemming from a need for a better structure of the information available. Thus they are dedicated to students and scholars with the mention that they are suitable for modification in order to better fit individual needs. They are a methodology and a model much rather than a final product which is yet a project in progress.

Chronology and timelines themselves are constitute one of the first lessons in the study of history since the principle of time framing an event or an era is vital to the understanding of the field (Păun 81). Timelines can vary from simple - those that mark on the axis of time the main cultures and epochs of humanity - to more complex ones that are further divided into shorter time spans (Felezeu 100). One of the main principles on which timelines are based is that of causality, which is considered as one of the most important phenomena in the study of history. This is 
based on the belief that the same set of causes will provide the same effect, so that any slight difference in the causes or context will necessarily generate different effects (Felezeu 82).

History itself should not be perceived as isolated, but in a tight interdependency and causality as things are in reality (Felezeu 86). The human connections and relations between the artist need to be understood since they are not some characters living in a proverbial ivory tower, and timelines manage to make this human dimension seen much more easily, preventing the history of art to resemble a row call of names, artworks and stylistic characteristics.

The schematic aspect of any data visualization should not fall into irrelevant details, and it must be mentioned that the point of the timelines in not to teach/memorize dates, but rather to better understand the systematic correlations that further help in the creation of a critical opinion yet one that is firmly based on the available data. Learning becomes dysfunctional when useless dates are forced in the forefront in the disservice of a global, holistic understanding that offers a historical culture (Felezeu 107).

Another educational principle that stands at the base of these chronological timelines is that of the comparison. This is the process through which a phenomenon from the past is explained by analyzing the similarities and the differences between historical events (Felezeu 183). This comparison can be of two different kinds both of which can be explored through this type of data visualization. Firstly there is the concomitant comparison which implies the analysis of facts and events in the same period but in different conditions. Such an example is the Baroque art from protestant Netherlands and the one in catholic Spain. This is extremely useful for establishing connections and comparing two coexisting styles, or contemporary artists, or even connecting fields in order to identify a similitude. The second kind of comparison is a successive one, namely the comparison between similar notions or events that happed in different times. Timelines are also useful in this situation, for example an analysis on the evolution of the portrait and its typology in various historical periods, and noticing their similarities and differences.

Timelines are meant also to counteract the unnecessary fragmentation of art history that comes as a consequence of a style-based teaching. It is also the case that most books are organized on chapters that present the art of the same period in different geographical areas (Tafrali), but timelines help implement in the viewers conscience that things often happened simultaneously, in direct connection to one another, and they annul the dangers of lacking a larger vision. They can also be useful for better integrating functional knowledge. One can choose any "slice" of time and check the social realities in different corners of the world - how many Romanians 
realize that Mihai Viteazul (1558-1601) was William Shakespeare's (1564-1616) contemporary? The presence of timelines in Gombrich's iconic volume suffices as demonstration for their utility alongside maps which are already consecrated as tools for teaching history (Păun 103). The digital medium could eventually even provide a means for combining the two in one vivid and relevant visualization.

Despite the fact that it cannot be completely overrun, the presented timelines are as objective as scholarly possible without any political or ideological manipulations, or even less justified personal preference (Căpiță, Căpiță 94). However the bias is still there due to the inescapable eurocentrism that plagues the textbook study of art history in general.

\section{Conclusions}

Recently the literature seems to have opened up towards the utility of timelines and their usage in the study of art history, such as the work of $G$ which can be seen as a popularization book. This is also natural since timelines are educational tools rather that expert and scholarly ones and they focus on enhancement of previous knowledge and its quick delivery, which in reality marks a trend in this direction. However the true span of this raise in interest can be seen on the internet where there are a large and constantly increasing number of websites that include ample timelines (The Metropolitan Museum, The Art Story, Art History for Dummies) or even are dedicated solely to them (Oxford Art Online, Arty Factory). The visual element of these chronological charts as well as their complexity makes them highly suitable for the digital environment, and thus there is little surprise that in a true Digital Humanities fashion there are a number of free tools where users can create and curate their own timeline (Timeline JS) one even quoting Albert Einstein in saying that the timeline is "a great visualization of any data in the $21^{\text {st }}$ century" (Time Graphics). This of course opens up a great realm of possibilities for both timelines and their users, and the general direction continues to be interdisciplinary and visual with elements that can only continue to increase in the complexity of the information they deliver through ever simpler and clearer means. 


\section{Works Cited}

*. "Pictura Barocă”, Editura Fundației Culturale Române, Bucharest, 1999.

A. Admiraal. "The History Timeline Chart", Agora, Vol. 47, No. 1 (2012), pp. 53-59.

Art History for Dummies. https://www.dummies.com/education/artappreciation/ arthistory-timeline/.

Arty Factory. http://www.artyfactory.com/art_appreciation/timelines/ art_history_timelines.htm.

L. Căpiță, C. Căpiță. "Tendițe în didactica istoriei”, Editura Paralela 45, Bucharest, 2005.

C. Felezeu. "Didactica istoriei”, Presa Universitară Clujeană, Cluj-Napoca, 2000.

D. Gariff. "Cei mai influenți pictori din lume și artiștii pe care i-au inspirat", Enciclopedia RAO, Bucharest, 2008.

E. H. Gombrich. "Istoria Artei”, Pro Editură și Tipografie, Bucharest, 2007.

A. Hauser. "The Social History of Art", Vol. I, Routledge, London, 2006.

I. Marin. "Pictura Prerafaelită sub semnul narativului", Meridiane, Bucharest, 2003.

Oxford Art Online. http://www.oxfordartonline.com/page/timelines-of-world-art.

Ș. Păun. "Didactica istoriei”, Corint, Bucharest, 2001.

J. Rewald. "Postimpresionismul", Meridiane, Bucharest, 1978.

J. Ruskin. "On Art and Life", Penguin Books, London, 2004.

O. Tafrali. "Manual de istoria artelor", Vol I-II, Editura Cartea Românească, Bucharest, 1927.

M. Tătaru. "Caspar David Freidrich”, Meridiane, Bucharest, 1974.

The Art Story. Modern Art Insight. https://www.theartstory.org/section_timelines.htm.

The Metropolitan Museum. Heilbrunn Timeline of Art History.

https://www.metmuseum.org/toah/chronology/.

Time Graphics. https://time.graphics/.

Timeline JS. https://timeline.knightlab.com/.

N. Wolf. "Romanticism", Taschen, 2007. 